\title{
The Performance Edge: Strategic and Value Dissensus
}

\author{
Cathy A. Enz, Cornell University \\ Charles R. Schwenk, Indiana University
}

\begin{abstract}
The study discussed in this article deals with the effects of strategic and value consensus on the performance of management teams in operating units at a large multinational company. The results showed that diversity of views on objectives, competitive methods, and values are positively related to objective measures of performance but negatively related to managers' own perceptions of their operating units' performance. This suggests that diversity of views may allow managerial employees to fulfill their responsibilities more effectively by improving their units' performance. Possible explanations for these results are discussed in the concluding section of this article.
\end{abstract}

The effects of conflict and diversity of views on managerial decision making and company financial performance have been the subject of numerous recent studies (Bourgeois, 1980, 1985; Dess, 1987; Schweiger et al, 1986; Schwenk, 1982, 1988; Tjosvold, 1985). Though the results of these studies are not entirely consistent, the weight of evidence favors the view that conflict and diversity can improve the quality of decisions and company performance.

In this paper, we will review the evidence for the positive effects of diversity of views on strategic objectives, competitive methods, and values. We will then report on the results of a study dealing with the effects of these types of diversity on the performance of operating units at a large multinational organization.

\section{Past Research on Consensus and Performance}

Before discussing past research it is necessary to provide some definitions of terms. The term "consensus" as used in this article is defined as the degree of agreement among members of a management team about the relative importance of individual objectives, competitive methods, or organizational values. The term "objectives" refers to the basic goals of a business such as profits, sales growth, and firm prestige or reputation. "Competitive methods" refers to the means of achieving 
objectives. These might include new product development, an emphasis on cost or quality control, and customer service. Organizational values are concerned with what "ought to be" or what is desirable in the running of the firm. These values might include professionalism, aggressiveness, creativity, efficiency, and product quality.

As mentioned earlier, a good deal of research has examined the effects of consensus on performance. This research will be discussed next.

\section{Consensus on Objectives}

Two studies by Bourgeois suggest that consensus on objectives may be negatively related to performance. Bourgeois (1985) collected information on the perceptions of environmental uncertainty and organizational objectives from 99 top-level executives in 20 firms. He found that consensus on perceived environmental uncertainty and consensus on objectives were associated with lower financial performance. He also found that consensus on objectives was negatively correlated with overall accuracy of the perception of environmental uncertainty within firms.

Based on the results of this study. Bourgeois argued that executives in organizations with declining performance may attempt to suppress differences and disagreements and encourage consensus which they feel is necessary for improved performance (1985, p. 562). However, this may produce a kind of "groupthink" (Janis, 1972; Janis \& Mann, 1977), which reduces the accuracy of environmental perceptions and the quality of company strategy. Thus, the results of this study support his assertion that " . . attempts ... to gather complete agreement may be more deleterious than helpful and actually impede performance" (1985, p. 571).

These results extend those of an earlier study by Bourgeois (1980). Using data from interviews with 12 CEO's and questionnaire responses by 67 top-level executives, he determined that lack of consensus (dissension) on objectives and consensus on competitive methods was associated with higher performance whereas consensus on objectives and dissension on competitive methods led to the worst performance.

However, Dess (1987) examined the relationship between organizational performance and consensus within top management teams in 19 paints and allied products companies. He found that consensus on objectives and on competitive methods was positively related to performance and concluded "it is equally important for the top management team to seek consensus on either the company's objectives or its competitive methods" (1987, p. 273). Dess suggested that the differences 
between his results and those of Bourgeois were due to differences in the samples used and in the methods of analyzing the results.

Thus, this research has produced conflicting results. Bourgeois argues that a management with diverse views has a larger number of alternative approaches for dealing with strategic problems. Disagreement between proponents of these views helps ensure more thorough analysis and more effective strategy formulation. This argument is consistent with research on decision aids like dialectical inquiry and devil's advocacy which introduce controversy into the decision process and produce higherquality decisions (Schwenk, 1988; Tjosvold, 1985). Dess, on the other hand, suggests that management teams with high consensus may have better understanding of the appropriate strategies for their companies and better communication among themselves, which leads to better performance.

\section{Consensus on Competitive Methods}

The results of the research dealing with consensus on competitive methods seem somewhat more consistent than those of the research on objectives. Bourgeois (1980), in the study described in the previous section, found a positive relationship between consensus on competitive methods and company performance. Dess (1987) also found a positive relationship between this type of consensus and company performance.

Hrebiniak and Snow (1982) assessed the degree of agreement among top management teams on firms' strengths and weaknesses (which should be related to competitive methods) and found a positive relationship between this agreement and firm performance defined in terms of return on net assets. Though they did not measure consensus on objectives of competitive methods, their results are consistent with those of Dess (1987).

Thus, this research has produced a consistent set of results. Consensus on competitive methods is positively related to performance.

\section{Consensus within Operating Units}

The discussion of past research on within-company consensus and performance presented earlier in the article will be used to develop hypotheses about the relationship between consensus and performance within operating units of an organization. Though there is some research suggesting that consensus on objectives is positively related to performance, the weight of evidence seems to favor a negative relationship. The researchers who have shown a negative relationship between performance and consensus have argued that diversity of views within top management teams improves decision making and company performance. If this is true, these same processes should improve decision making 
and performance in operating unit management teams. This yields the prediction that within-operating unit consensus on objectives will be negatively related to operating unit performance. On the other hand, past research suggests that within-operating unit consensus on competitive methods will be positively related to performance.

This suggests the following hypotheses:

HI: Within-operating unit consensus on operating unit objectives will be negatively related to operating unit performance.

$\mathrm{H} 2$ : Within-operating unit consensus on competitive methods will be positively related to performance.

\section{Value Consensus}

Past research has also addressed the relationship between value consensus and performance. Superior performance is the result of strongly held, shared values according to many writers (Barney, 1986; Deal \& Kennedy, 1982; Peters \&. Waterman, 1982). Writers have spoken of the valuesperformance connection in accounts of the success of the Japanese system of management (Ouchi, 1981; Pascale \& Athos, 1981). Others have noted that values play a dominant role in strategic choices and decision making (Barnard, 1938; Child, 1972; Enz, 1989; Hambrick \& Mason, 1984). Guth and Tagiuri (1965) concluded that top managers' value systems strongly influence their organizations' performance. In spite of the frequent suggestion that agreement on values influences organizational performance, researchers have not empirically linked value consensus to financial performance (Saffold, 1988). Fifteen years ago Conner and Becker (1975) bemoaned the lack of empirical research on the relationship between values and performance, while Hambrick and Brandon note that "Regrettably, the situation today remains the same" (1988, p. 24). Consensus on values within unit management teams is worthy of investigation because these groups are directly responsible for strategy implementation and accountable for the performance of the operating units. Hence the present investigation examines value consensus within operating unit management teams in an effort to ascertain their relationships with performance.

Values are standards or preferences that influence the selection of means and ends of action, but are independent of specific situations. Enz has specifically defined organizational values as "... beliefs held by an individual or a group that speak to the actions and goals (ends) organizations 'ought to' or 'should' identify in the running of the enterprise. Organizational values specify which business 
actions or objectives are preferable to alternate actions or corporate objectives" (1986, p. 27). This definition of organizational values will be employed in the present study.

Attempts to specifically focus on shared values and empirically examine the relationship between value consensus and performance have been few and limited primarily to dyadic relationships and personal values. Senger (1971), for example, found that supervisors rated value-similar subordinates as more competent. In an effort to improve on the serious methodological flaws of the previous studies, namely, consistency effects and common-method bias, a recent study using multiple measures of value agreement and performance found value consensus to be unrelated to performance (Meglino et al, 1988). This study succeeded in rectifying the methodological deficiencies of previous studies exploring dyadic relationships; however, the true relationship between value consensus and performance is still unknown, given the equivocal nature of the study's findings.

While conventional wisdom and anecdotal reports from the practitioner literature would suggest that a positive relationship should exist between value consensus and performance, there are equally compelling reasons to argue for relationships in the opposite direction. Recent discussions of the "dark side" of culture suggest that shared meanings may have adverse affects on a variety of organizational out comes (Dalton \& Enz, 1987). Some group studies have revealed that homogeneity sometimes harms performance (Janis, 1972; Beyer \& Trice, 1978).

It is expected that value consensus within operating unit management teams will be associated with the degree of unit performance. The direction of the relationship is a subject of speculation and not readily evident. It may be that within-unit value consensus will be associated with higher unit performance because employees will be more effective at internal communication, more efficient in decision making, more consistent in implementing strategy, and more likely to follow similar behavior patterns (Sathe, 1985; Schein, 1985).

On the other hand, value consensus may be associated with lower performance levels because employees lack sufficient diversity to adapt to changes in the environment or sufficient variety to challenge and innovate. The work of Bourgeois (1985) supports this view that similarity/consensus may result in poor performance.

In light of the arguments suggesting both positive and negative effects and the lack of empirical support that directly addresses the value consensus-performance linkage, the following hypothesis is offered:

H3: Value consensus within-operating unit management teams will be associated with unit performance. 


\section{Methods}

\section{Data Collection}

This study dealt with operating units within a large transportation organization. These units are regionally decentralized and the personnel in each unit perform similar activities and provide an identical service within numerous geographic areas. Each unit is managed by a senior manager and from one to five assistant managers. In addition to these managers, each unit has from 25 to several hundred personnel. The responses of unit managers to a mailed questionnaire provide part of the data used in the current study. Surveys were mailed to the managers of 400 of a total of 600 units. Two-hundred fifty-six units returned one or more questionnaires. Units with only one manager responding to the survey were omitted, leaving a sample of 135 operating units. Comparison of the respondents with the non-respondents revealed no obvious differences in terms of operating unit characteristics or performance. We received responses from the entire management team in 84 of the units, from all but one member of the team in 25 of the units, all but two members of the team in 21 of the units, and all but three members in five of the units.

\section{Performance Measures}

While previous research dealing with performance and consensus has focused on measures of overall company performance such as return on assets, earnings, and sales (Bourgeois, 1985; Dess, 1987), it was necessary in this study to focus on performance measures for elements of operating unit activities that contribute to overall company performance. Since the operating units are not profit centers it is not possible to collect information on return on assets or earnings from them.

Company managers identified two primary performance measures which contribute to overall company revenues. These were operating unit service volume and sales volume. Service and sales volumes measure the amount of product sold and delivered by each operating unit. These two volume measures indicate how much each operating unit contributes to company sales, one of the measures used by both Bourgeois and Dess. The two measures of efficiency used were service efficiency and sales efficiency. These dealt with the volume of product sold and delivered per unit of input. These would contribute to the ROE and earnings measures used by Bourgeois and Dess.

Finally, we asked each operating unit manager to assess his own unit's performance. Two subjective indicators of general performance were used. One measure asked each unit manager to evaluate the performance of his or her unit compared to other units within the company. The managers indicated their station's general performance on a 5-point Likert scale which ranged from "Top 20\%" to 
"Lowest 20\%." This measure was similar to that used by Lawrence and Lorsch (1967). The second subjective measure asked managers to assess their own unit's overall performance. Equating $100 \%$ to the best the unit could do, respondents indicated what percent of this ideal their unit was currently achieving.

\section{Strategic Consensus}

Consensus on objectives and competitive methods was measured using scales similar to the ones used by Bourgeois and Dess but with modifications to reflect the unique aspects of the company we were studying. Respondents were asked to indicate the importance of each objective and competitive method using a 5-point scale ranging from "extremely important" to "not at all important." Within operating unit consensus was calculated in the same way Dess (1987) calculated consensus within top management teams.

\section{Value Consensus}

Value consensus within each operating unit's management team was calculated by summing the standard deviations within each management team on questions of value importance for each of 20 value items taken from the organizational value congruence scale (Enz, 1986). This scale lists and briefly describes organization- based values such as efficiency, product quality, profits, professionalism, and ethical behavior. Operating unit managers were asked to indicate the importance of each value using a 5-point scale ranging from "not at all important" to "extremely important." For purposes of explanatory clarity, the direction of the scores was reversed so that they represent similarity.

The advantages of the measures and measurement strategies employed in this study are worthy of brief discussion. First, the use of operating unit data rather than individual data to measure value consensus controls for operating unit size variation across the 135 locations and provides findings less distorted by individual biases. Secondly, the use of secondary source financial performance data reduced the likelihood that response bias might explain observed correlations. Finally, using financial performance data at the operating unit level of analysis allows for unambiguous comparability of one unit to another. Unlike performance data at the firm level, the objective performance measures obtained in this study allow for data that are consistently and uniformly collected from the same source (i.e., corporate headquarters), in the same manner, over the same period of time. 
Table I. Pearson Product-Moment Correlations

\begin{tabular}{|c|c|c|c|c|c|c|c|c|c|}
\hline Variables & 1 & 2 & 3 & 4 & 5 & 6 & 7 & 8 & 9 \\
\hline $\begin{array}{l}\text { 1. Strategic consensus on } \\
\text { unit objectives }\end{array}$ & - & & & & & & & & \\
\hline $\begin{array}{l}\text { 2. Strategic consensus on } \\
\text { competitive methods }\end{array}$ & $0.48^{b}$ & - & & & & & & & \\
\hline 3. Value consensus & $0.43^{b}$ & $-0.55^{b}$ & - & & & & & & \\
\hline $\begin{array}{l}\text { 4. Perceived overall per } \\
\text { formance }\end{array}$ & 0.09 & 0.002 & $0.23^{c}$ & - & & & & & \\
\hline $\begin{array}{l}\text { 5. Perceived general per } \\
\text { formance }\end{array}$ & $0.22^{c}$ & 0.02 & $0.18^{d}$ & $0.69^{b}$ & - & & & & \\
\hline 6. Sales volume & $-0.21^{c}$ & $-0.16^{d}$ & $-0.28^{b}$ & 0.01 & -0.04 & - & & & \\
\hline 7. Service volume & $-0.20^{d}$ & -0.14 & $-0.23^{c}$ & 0.01 & -0.03 & $-0.96^{b}$ & - & & \\
\hline 8. Sales efficiency & $-0.18^{d}$ & $-0.21^{c}$ & $-0.21^{c}$ & 0.01 & -0.12 & $0.44^{b}$ & $0.45^{b}$ & - & \\
\hline 9. Service efficiency & $-0.16^{d}$ & $-0.18^{d}$ & $-0.18^{d}$ & -0.001 & $0.14^{d}$ & $0.49^{b}$ & $0.57^{b}$ & $0.86^{c}$ & - \\
\hline
\end{tabular}

${ }^{a}$ The first two performance measures are subjective global assessments and the next four performance measures are objective indicators obtained from archieved records for 1988.

${ }^{b} p<0.05$.

$c_{p}<0.01$.

${ }^{d} p<0.001$.

\section{Results}

The first hypothesis, that within-unit managerial consensus on unit objectives would be negatively related to unit performance, was supported for all four of the objective (archival) indicators of volume and efficiency (Table I). The highest performing units were those with the greatest degree of disagreement on strategic objectives. In contrast, perceived overall performance was not significantly related to consensus on objectives, and perceived general performance yielded significant results that contradicted the hypothesized relationship.

Hypothesis 2, which predicted that consensus on competitive methods would be positively related to performance, was not supported. Contrary to the hypothesis, the data show that for all four objective performance indicators (Table I), the highest performing units were those with the greatest degree of disagreement on competitive methods. Consensus on competitive methods was not significantly related to either measure of perceived performance.

The third hypothesis that value consensus within management teams is related to unit performance was strongly supported for all six performance indicators. The analyses yielded the same pattern of findings as the analyses of strategic consensus. The highest performing units were those with the greatest degree of dissimilarity on organization-based value preferences. Further, unit management team value consensus was positively related to both indicators of perceived unit performance. 
Table II. Multiple Regression Analyses of Consensus on Objective and Subjective Operating Unit Performance

\begin{tabular}{lcc}
\hline \multicolumn{1}{c}{ Performance models } & \\
\hline & $F$-Tests & $R^{2}$ \\
\hline 1. Perceived overall performance & $2.69^{b}$ & 0.07 \\
2. Perceived general performance & $4.56^{c}$ & 0.11 \\
3. Sales volume & $3.91^{c}$ & 0.09 \\
4. Service volume & $2.76^{b}$ & 0.07 \\
5. Sales efficiency & $2.80^{b}$ & 0.07 \\
6. Service efficiency & 1.80 & 0.02 \\
\hline
\end{tabular}

\footnotetext{
${ }^{a}$ All regression models included value consensus, strategic consensus on competitive methods, and strategic consensus on operating unit objectives as the independent variables.

${ }^{b} p<0.05$.

${ }^{c} p<0.01$.
}

The objective archival indicators of performance were all highly correlated with each other, and the two subjective appraisals of unit performance were also highly correlated (Table I). In contrast, the correlations between the objective and subjective indicators were insignificant in all but one instance, and yielded generally negative relationships. The pattern of relationships revealed that managers perceived their unit to be a high performer when archival indicators reported low performance; however, the linkage between subjective and objective performance indicators was tenuous.

Six supplemental regression analyses were performed to gain clearer insight into the predictive power of the strategic and value consensus variables. In these regression models dependent variables are the six indicators of performance (Table II). Five of the six F-tests yielded significant explanations for variation in performance, with the variance accounted for ranging from a low of $2 \%$ to a high of $11 \%$. Value consensus generally proved to be the most significant predictor of performance. Consistent with the findings noted earlier, the direction of effect suggested that value dissent predicted objective performance and value consensus explained subjective performance. It is worthy of note that the variance explained was small although significant in all but one model.

\section{Discussion}

This study showed that within-operating unit consensus on objectives and competitive methods was negatively related to all of our objective measures of performance. The explanations for the negative relationship between consensus among top management teams and company performance in Bourgeois' 1985 study may also apply to these results. Each unit operates in a different geographic 
region where different bases of service may be important to good performance. Diversity of views and disagreement on the relative importance of different operating unit objectives may stimulate operating unit management to question their assumptions and more carefully consider the information they have about customer desires with respect to each of their objectives. This in turn may lead to more accurate perceptions, more effective effort, and better performance. This explanation is consistent with previous research on techniques for stimulating conflict and controversy in strategic decision making (Schweiger, Sandberg, \& Ragan, 1986; Schwenk, 1982, 1988; Tjosvold, 1985). These studies have demonstrated that the presence of diverse views about a strategic problem and the open discussion of these views improves the process of decision making and leads to higher performance.

It seems that different types of diversity are relatively more important in statistically explaining different measures of performance. Value consensus seems to be the most important variable in explaining objective performance. One possible explanation for this is that value similarity is actually more important than strategic consensus in producing differences in performance. Since values deal with situationally independent fundamental premises people hold about the way they should behave with each other, diversity on values may lead to deeper and more fundamental questioning of assumptions than diversity in beliefs about company objectives. This assumption-questioning may lead to more thorough discussion and analysis of problems. It is possible that value dissent must precede strategic dissent and hence fosters a tolerance of differences that makes strategic dissent possible and functional. The greater importance of value dissension in predicting performance would suggest its role as a precursor to strategic disagreement.

It is important to address the difference in performance measures. All the correlations between the independent variables and performance for the objective measures were negative, indicating that diversity is positively related to performance. The correlations for the subjective measures, however, indicate that consensus and similarity lead to higher perceived performance. It may be that operating unit managers believe their performance is better when they are in clear agreement.

If, as Bourgeois suggests, management teams prize agreement on objectives and seek to enforce or strengthen it, the result may be a kind of groupthink which leads them to believe they are performing at a higher level than they are. This same groupthink might reduce performance by reducing the diversity which stimulates debate, more thorough analysis of problems, and the generation of a greater number of creative alternatives for dealing with them. The effect of this consensus might be a significant divergence between an operating unit's actual performance and management's evaluation of its performance. 
The different findings for objective and subjective measures of performance provide an opportunity to speculate on how unit managers may fail. Consensus on values and strategic issues seem to increase the probability that managers might manipulate their perceptions of unit performance. Consensus may produce a collective view of performance, but may not be worth striving for when objective performance suffers. Units free of disagreement may be doomed to fail because of their inherent inflexibility, their inability to cope with environmental changes, and their unwillingness to challenge the status quo.

In conclusion, the belief that value and strategic disagreement must be resolved or controlled fits a common view that conflict is destructive. This study has provided a countervailing view that dissent may be best for unit performance. It is possible that unit cooperation can be based on mutual adjustment of differences, challenging of assumptions, or compromise. In essence the performance edge may be the result of organizational units that foster tolerance for differences in strategic and value factors thereby producing an adaptive unit with a greater appreciation of multiple perspectives.

\section{References}

Barnard, C. I. (1938). The Function of the Executive, Cambridge, MA: Harvard University Press.

Barney, J. B. (1986). Organizational culture: Can it be a source of sustained competitive advantage? Academy of Management Review, 11(3), 656-665.

Beyer, J. M., \& Trice, H. M. (1978). Implementing Change. New York: Free Press.

Bourgeois, L. (1980). Performance and Consensus. Strategic Management Journal, 1, 227-248.

Bourgeois, L. (1980). Strategic goals, perceived uncertainty, and economic performance in volatile environments. Academy of Management Journal, 28, 548-573.

Child, J. (1972). Organizational structure, environment, and performance: The role of strategic choice. Sociology, 6, 2-22.

Connor, P. E., \& Becker, B. W. (1975). Values and the organization: Suggestions for research. Academy of Management Journal, 18, 550-561.

Dalton, D. R., \& Enz, C. A. (1987). Absenteeism in remission: Planning, policy, culture. Human Resource Planning. 10(2), 81-91.

Deal, T. E., \& Kennedy, A. A. (1982). Corporate Cultures: The Rites and Rituals of Corporate Life, Reading, MA: Addison-Wesley.

Dess, G. (1987). Consensus on strategy formulation and organizational performance: Competitors in a fragmented industry. Strategic Management Journal, 8, 259-278. 
Enz, C. A. (1986). Power and Shared Values in the Corporate Culture, Ann Arbor, MI: UMI Research Press.

Enz, C. A. (1989). The relationship between organizational value sharing and influence over strategic decisions. International Journal of Value-Based Management.

Guth, W. D., \& Tagiuri, R. (1965). Personal values and corporate strategy. Harvard Business Review, 43(^5), 123-132.

Hambrick, D. C, \& Mason, P. A. (1984). Upper echelons: The organization as a reflection of its top managers. Academy of Management Review, 9(2), 193-206.

Hrebiniak, L., \& Snow, C. (1982). Top management agreement and organizational performance. Human Relations, 35, 1139-1158.

Janis, I. (1972). Victims of Groupthink, Boston: Houghton-Mifflin.

Janis, I., \& Mann, L. (1977). Decision Making: A Psychological Analysis of Conflict, Choice, and Commitment, New York: Free Press.

Lawrence, P., \& Lorsch, J. (1967). Organization \& Environment. Homewood, IL: Irwin.

Meglino, B. M., Ravlin, E. C, \& Adkins, C. L. (1988). A work values approach to corporate culture: A field test of the value congruence process and its relationship to individual outcomes. Paper presented at the annual meeting of the Academy of Management, Anaheim, California.

Ouchi, W. G. (1981). Theory Z, Reading, MA: Addison-Wesley.

Pascale, R. T., \& Athos, A. G. (1981). The Art of Japanese Management: Applications for American Executives. New York: Simon \& Schuster.

Peters, T., \& Waterman, R. (1982). In Search of Excellence: Lessons from America's Best-Run Companies. New York: Harper \& Row.

Saffold, G. S. (1988). Culture traits, strength, and organizational performance: Moving beyond "strong" culture. Academy of Management Review, 13(4), 546-558.

Sathe, V. (1985). How to decipher and change corporate culture. In Kilmann, R. H., Saxton, M. J., Serpa, R., et al (eds.), Gaining Control of the Corporate Culture, 260-261. San Francisco: Jossey-Bass.

Schein, E. H. (1985). Organizational Culture and Leadership. San Francisco: Jossey-Bass.

Schweiger, D., Sandberg, W., \& Ragan, J. (1986). Group approaches for improving strategic decision making: A comparative analysis of dialectical inquiry, devil's advocacy, and consensus. Academy of Management Journal, 29, 51-71.

Schwenk, C. (1982). Effects of inquiry methods and ambiguity tolerance on prediction performance. Decision Sciences, 13, 207-221.

Schwenk, C. (1988). The Essence of Strategic Decision Making. Lexington, MA: Lexington Books. 
Senger, J. (1971). Managers' perceptions of subordinates' competence as a function of personal value orientations. Academy of Management Journal, 14, 415-423.

Tjosvold, D. (1985). Managerial implications of controversy research. Journal of Management, 11, 221238. 